\title{
Association of Normal-Range Hemoglobin Alc Value During Midpregnancy with Adverse Birth Outcomes
}

\author{
Lihua Zhang ${ }^{1,2}$ \\ Ruixia Zhai ${ }^{1}$ \\ Zhiyu Huo' \\ Zhenyan Wei ${ }^{1}$ \\ Ziheng Zhang ${ }^{2}$ \\ Ruirui Wei' \\ Dongmei Man ${ }^{1,2}$ \\ 'Department of Obstetrics, Affiliated \\ Hospital of Jining Medical University, \\ Jining, Shandong, People's Republic of \\ China; ${ }^{2}$ College of Clinical Medicine, \\ Jining Medical University, Jining, \\ Shandong, People's Republic of China
}

Correspondence: Dongmei Man Email mandongmei@I63.com
Background: The midpregnancy normal-range HbAlc value and adverse birth outcomes were controversial. To address this lack of data, we examined the associations between midpregnancy normal-range HbA1c value and adverse birth outcomes.

Objective: To evaluate whether an association exists between the midpregnancy normalrange $\mathrm{HbA1c}$ value and adverse birth outcomes.

Materials and Methods: A total of 8389 women in their midpregnancy with normal gestational HbA1c value from the Affiliated Hospital of Jining Medical University in China participated in this study from January to December 2019. Subjects were stratified on the basis of their midpregnancy $\mathrm{HbAlc}$ value, and multivariate logistic regression was implemented to investigate the association between different $\mathrm{HbAlc}$ values and adverse birth outcomes.

Results: Incidence of preterm birth, macrosomia, and large for gestational age (LGA) for 8389 subjects were $4.8 \%, 6.3 \%$ and $16.5 \%$, respectively. The multivariate logistic regression model demonstrated that the risk of preterm birth (adjusted odds ratio [OR]: 1.71 and 95\% confidence interval [CI]: 1.25-2.34), macrosomia (OR: 1.68 and 95\% CI: 1.26-2.22), and LGA (OR: 1.53 and 95\% CI: 1.28-1.83) increase for every increase of $1 \%$ maternal HbAlc. Women with a prepregnancy body mass index (BMI) of $<25 \mathrm{~kg} / \mathrm{m}^{2}$ have a stronger correlation with HbAlc values and adverse birth outcomes than women with a prepregnancy BMI of $\geq 25 \mathrm{~kg} / \mathrm{m}^{2}$.

Conclusion: Our results indicated that the midpregnancy normal-range HbA1c level within the normal range is associated with adverse birth outcomes. Monitoring and controlling HbAlc may reduce the risk of adverse birth outcomes.

Keywords: hemoglobin A1c, pregnant women, normal-range, midpregnancy, adverse birth outcomes

\section{Introduction}

Adverse birth outcomes, including preterm birth, macrosomia, and large for gestational age (LGA), are critical health problems. Fifteen million babies are born with poor birth outcomes annually worldwide. More than a million people die immediately after birth. ${ }^{1-3}$ These adverse birth outcomes may seriously affect the physical and mental health of pregnant women and neonates, threaten their quality of life, and bring heavy economic burden to the family and society. ${ }^{4,5}$ Clinical studies have shown that blood glucose values lower than diagnosed diabetes patients are related to adverse pregnancy outcomes. ${ }^{6-8}$ 
Hemoglobin A1c (HbA1c) is a substance formed by the reaction between the amino $(\mathrm{N})$ terminal of hemoglobin and hexose that offers an integrated summary of circadian blood glucose value during the preceding two to three months. The consensus panel of International Association of Diabetes and Pregnancy Study Groups recommended that $\mathrm{HbA} 1 \mathrm{c} \geq 6.5 \%$ may be used for the diagnosis of gestational diabetes mellitus (GDM), with $\mathrm{HbAl} 1 \mathrm{c} \geq 6.0 \%$ indicating a high risk of GDM. ${ }^{9,10}$

Meanwhile, relatively high but normal $\mathrm{HbA1c}$ values may be a potential risk factor for other nondiabetic conditions, such as cancers and brain, kidney, and coronary heart diseases. ${ }^{11-13}$ Studies have shown that differences in adverse pregnancy outcomes with $\mathrm{HbAlc}$ within the normal range are limited and results are inconsistent. A multicenter retrospective study conducted in Guangdong Province in China showed that normal elevated $\mathrm{HbA} 1 \mathrm{c}$ values were an independent risk factor for preterm birth, macrosomia, and LGA. ${ }^{14}$ A previous study showed that a significant correlation existed between $\mathrm{HbAlc}$ in the normal range and the risk of macrosomia but was absent with preterm birth and LGA. ${ }^{15}$ A study conducted at Kaiser Permanente Washington Hospital in 2019 showed that HbAlc within the normal range was not associated with adverse birth outcomes (premature infants, macrosomia, and LGA). ${ }^{16}$ The value of HbAlc showed a biphasic change during pregnancy, wherein the value was higher in the first and third trimesters but lower during midpregnancy. ${ }^{17}$ Therefore, our study aims to assess whether the increase in the normal range of $\mathrm{HbAlc}$ values of women during midpregnancy is related to the increased risk of adverse birth outcomes.

\section{Materials and Methods Study Participants}

The analysed data were extracted from the medical record information system of the Affiliated Hospital of Jining Medical University in Shandong Province, China. Data on 16,703 pregnant women who gave live birth in our hospital from January to December 2019 were successively collected. We included the following maternal information in this study: HbAlc values during midpregnancy, maternal age, prepregnancy body mass index (BMI), gestational week of delivery, and cesarean section. Neonatal information includes newborn's gender, birth weight, preterm birth, macrosomia, and LGA. Midwives with experience in the obstetrics department of our hospital were chosen for data entry. All staff members involved in the study were uniformly trained, acquired data were checked, medical records of missing items were retrieved, and medical records for logically incorrect data were recalled for error correction before data entry. Values were retaken from medical records for verification, and $10 \%$ of data were randomly selected for verification. This was a retrospective study. The data were anonymous, and the requirement for patient informed consent was therefore waived. Patient data confidentiality was kept and was in compliance with the Declaration of Helsinki. This study was approved by the human ethics committee of the Affiliated Hospital of Jining Medical University (2020C042).

\section{HbAlc Measurement}

Blood is drawn in the morning after a fasting period of at least 8 hours. The HbAlc value in the blood is measured using an ARKRAY HA-8180 automatic glycosylated hemoglobin analyzer (HA-8180) with the principle of ionexchange high-performance liquid chromatography.

\section{Exclusion Criteria}

Pregnant women below 18 years old, gestational weeks $\geq 42$ weeks, unspecified gestational weeks, birth weight $\geq 5000 \mathrm{~g}$, twin and triplet pregnancies, presence of fetal birth defects, gestational diabetes mellitus, prepregnancy diabetes mellitus and patients without data on HbAlc during midpregnancy were excluded from this study. A total of 8389 pregnant women were included in this study (Figure 1).

\section{Definition of Variables and Results}

1. Gestational weeks are determined on the basis of the last menstrual period (LMP) if the first or secondtrimester ultrasound agrees with the estimated due date (EDD) within 7 or 14 days, respectively. If the due date differs by more than 7 or 14 days in the first or second trimester, respectively, or if LMP is unknown, then EDD is changed to the date calculated by the earliest available ultrasound. ${ }^{18}$

2. Midpregnancy is within the 14 th to $27^{+6}$ th week of gestation.

3. Macrosomia is defined as an estimated fetal weight of more than 4000 g. ${ }^{19}$

4. LGA is determined according to the birth weight with the same gestational age average weight above the 90 th percentile. ${ }^{20}$ 


\section{Pregnant woman who delivered live births from January to December 2019 (N=16703)}

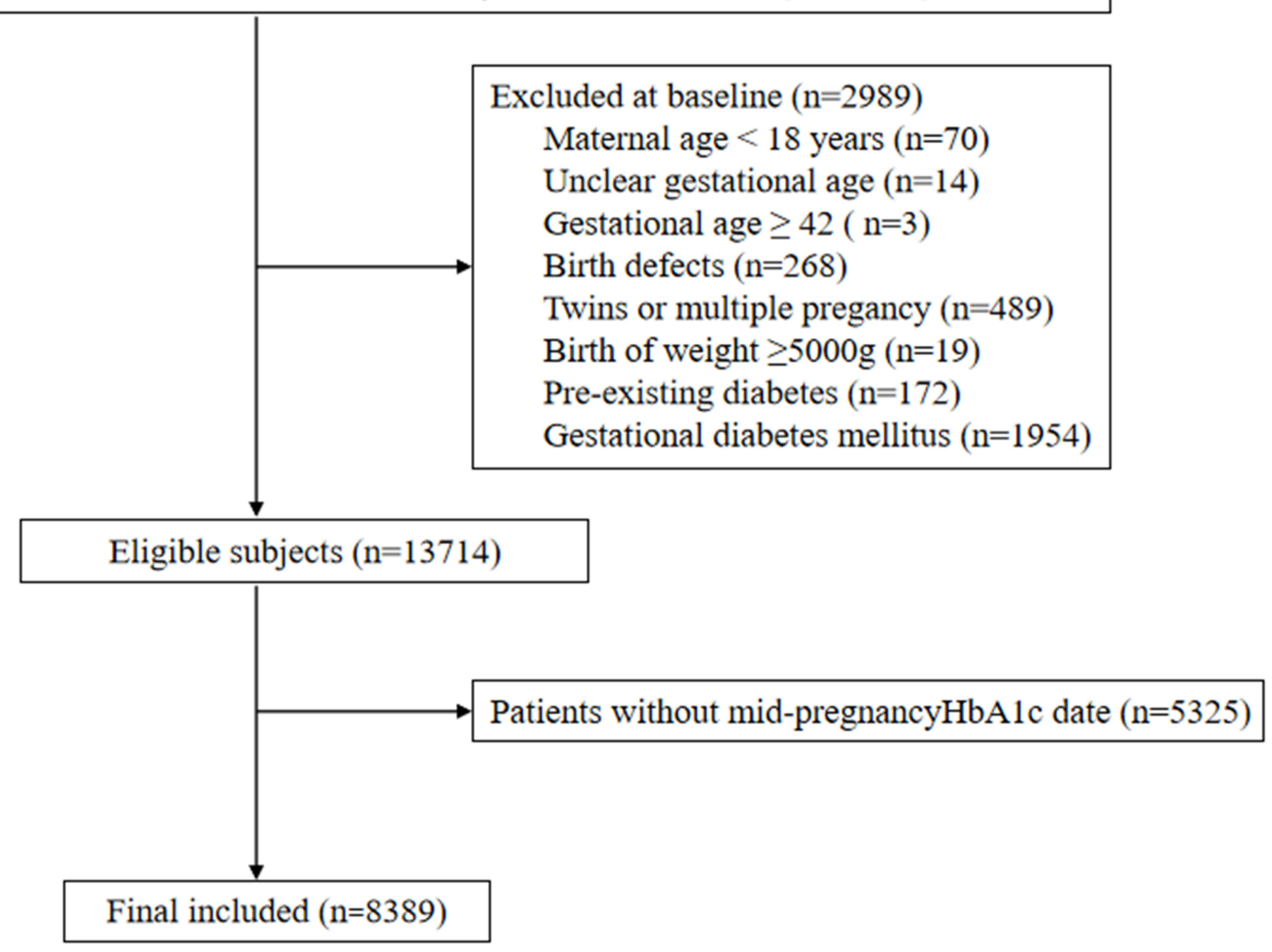

Figure I Flowchart of study population.

5. Preterm birth occurs within a gestational age of 28 weeks but less than 37 weeks. $^{21}$

\section{Statistical Analysis}

Mean and standard deviation were used as continuous variables, while number and percentage were utilized as categorical variables. The analysis of variance and chisquare test were applied to determine statistical differences between mean and proportion within the group, respectively. A total of 8389 subjects were grouped into four categories according to the quartile of $\mathrm{HbA1c}(\mathrm{Q} 1-\mathrm{Q} 4)$ : Q1: $\leq 4.7 \%$ ( $28 \mathrm{mmol} / \mathrm{mol})$, Q2: $4.8-4.9 \%(29-30 \mathrm{mmol} /$ $\mathrm{mol}), \mathrm{Q} 3: 5.0-5.1 \%(31-32 \mathrm{mmol} / \mathrm{mol})$, and Q4: $5.2-6.3 \%$ (33-46 mmol $/ \mathrm{mol}$ ). Furthermore, the following logistic models were listed: Model I includes two variables (maternal age and prepregnancy BMI) and Model II includes five variables (maternal age, prepregnancy BMI, gestational age at delivery, caesarean section, and sex).

Subgroup analysis was performed using a stratified linear regression model according to prepregnancy BMI $\left(<25\right.$ or $\geq 25 \mathrm{~kg} / \mathrm{m}^{2}$ ) (Figure 2). In addition, HbAlc values ranged from $5.7 \%$ to $6.4 \%$, which was defined by the American Diabetes Association as prediabetes because it

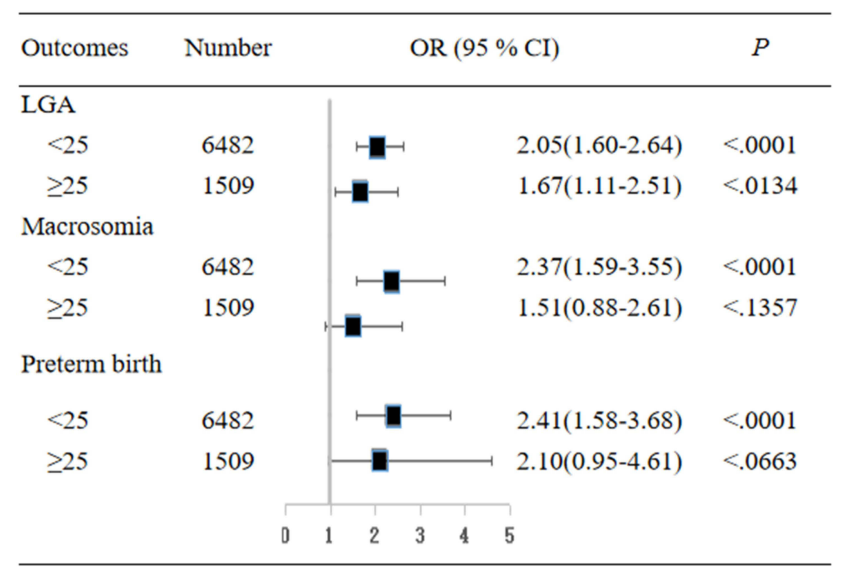

Figure 2 Associations between $\mathrm{HbAlc}$ level and adverse birth outcomes, stratified by maternal prepregnancy BMI $\left(\mathrm{kg} / \mathrm{m}^{2}\right)$.

Abbreviations: OR, odds ratio; LGA, large for gestational age.

can identify individuals with high risk of diabetes in the future. We performed a sensitivity analysis to exclude this subset of pregnant women and assess the stability of the results.

All analyses were performed with the statistical software packages R (http://www.R-project.org, The R Foundation) and Empower Stats (http://www.empowerstats.com; X 
\& Y Solutions, Inc.; Boston, MA, USA). $P$ values $<$ 0.005 (two-sided) were considered statistically significant.

\section{Results}

\section{Baseline Characteristics of Selected Participants}

A total of 8389 participants were selected for the final data analysis (Figure 1). Characteristics of mothers and newborns are summarized in Table 1. The mean maternal age (mean \pm SD) was $29.35 \pm 4.66$ years; prepregnancy BMI was $22.34 \pm$ $3.48 \mathrm{~kg} / \mathrm{m} 2$; When HbA1c was measured at (mean $\pm \mathrm{SD}$ ) was $25.31 \pm 1.14$, median of 25.29 weeks' gestation, the minmax (14.14-27.99); gestational week of delivery was 39.08 \pm 1.37 weeks; incidence of cesarean section was $57.24 \%$
(4802/8398), and incidence of boys was 53.83\% (4516/ 8398). The incidence of preterm birth, macrosomia, and LGA were $4.8 \%, 6.3 \%$, and $16.5 \%$, respectively.

\section{Univariate Analysis}

The results of univariate analyses are listed in Table 2. The results of univariate binary logistic regression showed that HbA1c (\%), maternal age, prepregnancy BMI, gestational age at delivery, birth weight, caesarean section, and sex were positively associated with adverse birth outcomes. Participants (8389 pregnant women) were divided into four groups according to the quartile of HbA1c (Q1-Q4). The incidence of preterm birth, macrosomia, and LGA increased significantly with the increase of HbAlc.

Table I Characteristics of the Study Population Based on HbAlc (\%) ( $n=8389)$

\begin{tabular}{|c|c|c|c|c|c|}
\hline HbAlc(\%) Category & $Q I \leq 4.7(n=\mid 88 I)$ & $\begin{array}{l}Q 2(4.8-4.9) \\
(n=2132)\end{array}$ & $\begin{array}{l}Q 3(5.0-5.1) \\
(n=2 \mid 23)\end{array}$ & $\begin{array}{l}Q 4(5.2-6.3) \\
(n=2253)\end{array}$ & $P$ \\
\hline Maternal age(yr) & $28.20 \pm 4.54$ & $29.06 \pm 4.53$ & $29.61 \pm 4.64$ & $30.33 \pm 4.68$ & $<0.001$ \\
\hline Gestational age at delivery (wk) & $39.22 \pm 1.26$ & $39.17 \pm 1.30$ & $39.07 \pm 1.38$ & $38.89 \pm 1.49$ & $<0.001$ \\
\hline Birth weight(g) & $3334.34 \pm 411.13$ & $3357.37 \pm 425.18$ & $3364.96 \pm 466.86$ & $3402.62 \pm 496.32$ & $<0.001$ \\
\hline Prepregnancy BMI $\left(\mathrm{kg} / \mathrm{m}^{2}\right)$ & & & & & $<0.001$ \\
\hline$<18.5$ & $293(15.58 \%)$ & $218(10.23 \%)$ & I 78 (8.38\%) & 90 (3.99\%) & \\
\hline $18.5-24.9$ & |29| (68.63\%) & 1524 (7I.48\%) & 1480 (69.7|\%) & I 408 (62.49\%) & \\
\hline $25-29.9$ & 142 (7.55\%) & 246 (II.54\%) & $327(15.40 \%)$ & $530(23.52 \%)$ & \\
\hline$\geq 30$ & $26(1.38 \%)$ & $5 \mathrm{I}(2.39 \%)$ & $54(2.54 \%)$ & $133(5.90 \%)$ & \\
\hline Not recorded & $129(6.86 \%)$ & $93(4.36 \%)$ & 84 (3.96\%) & $92(4.08 \%)$ & \\
\hline HbAlc of Gestational week & $25.06 \pm 1.04$ & $25.23 \pm 1.09$ & $25.39 \pm 1.07$ & $25.52 \pm 1.25$ & $<0.001$ \\
\hline Caesarean section & & & & & $<0.001$ \\
\hline No & 878 (46.68\%) & 925 (43.39\%) & 915 (43.10\%) & 868 (38.54\%) & \\
\hline Yes & $1003(53.32 \%)$ & $1207(56.61 \%)$ & 1208 (56.90\%) & $1384(6 \mid .46 \%)$ & \\
\hline Sex & & & & & 0.479 \\
\hline Female & 896 (47.63\%) & 985 (46.20\%) & 970 (45.69\%) & 1021 (45.32\%) & \\
\hline Male & 985 (52.37\%) & II 47 (53.80\%) & II 53 (54.3।\%) & 1232 (54.68\%) & \\
\hline LGA & & & & & $<0.001$ \\
\hline 0 & 1644 (87.40\%) & 1830 (85.83\%) & 1752 (82.52\%) & I 778 (78.92\%) & \\
\hline 1 & 237 (12.60\%) & 302 (14.17\%) & $37 \mid(17.48 \%)$ & 475 (21.08\%) & \\
\hline Macrosomia & & & & & $<0.001$ \\
\hline 0 & 1799 (95.64\%) & 2029 (95.17\%) & 1971 (92.84\%) & 2060 (91.43\%) & \\
\hline I & $82(4.36 \%)$ & 103 (4.83\%) & 152 (7.16\%) & $193(8.57 \%)$ & \\
\hline Preterm birth & & & & & $<0.001$ \\
\hline 0 & 1816 (96.54\%) & 2046 (95.97\%) & 2007 (94.54\%) & 2117 (93.96\%) & \\
\hline I & 65 (3.46\%) & 86 (4.03\%) & 116 (5.46\%) & 136 (6.04\%) & \\
\hline
\end{tabular}

Note: Data are presented as mean \pm standard deviation or $\mathrm{n}(\%)$.

Abbreviations: OR, odds ratio; Ref, reference; LGA, large for gestational age; 0, no; “I”, yes. 


\begin{tabular}{|c|c|c|c|c|c|c|c|c|c|}
\hline \multirow{3}{*}{ 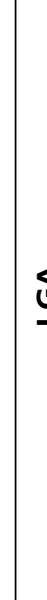 } & $a$ & $\begin{array}{l}\overline{8} \\
\text { ì } \\
\text { v }\end{array}$ & চे & 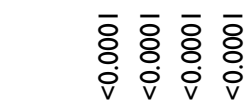 & $\begin{array}{l}\overline{8} \\
\dot{0} \\
\text { v }\end{array}$ & $\begin{array}{l}\overline{0} \\
\dot{0} \\
\dot{v}\end{array}$ & $\begin{array}{l}\overline{8} \\
\text { o } \\
\text { v }\end{array}$ & 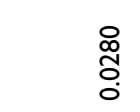 & 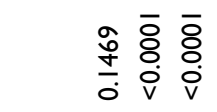 \\
\hline & 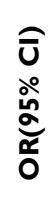 & 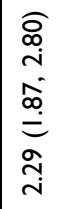 & 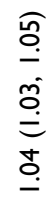 & 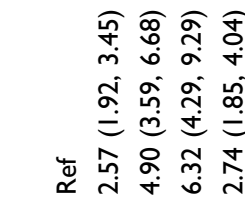 & 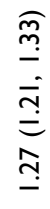 & 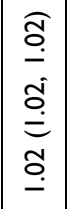 & 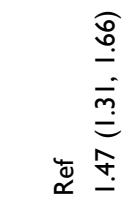 & 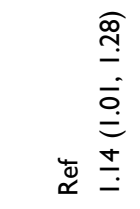 & 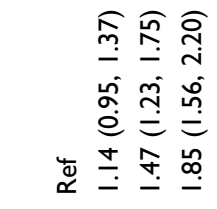 \\
\hline & $\frac{\mathscr{0}}{\frac{\pi}{\pi}}$ & 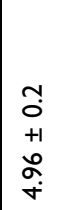 & $\begin{array}{l}\stackrel{0}{\circ} \\
\dot{+} \\
+1 \\
\stackrel{1}{0} \\
m \\
\stackrel{\sim}{2}\end{array}$ & 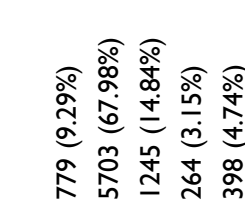 & $\begin{array}{l}\stackrel{\hat{m}}{=} \\
+1 \\
\infty \\
0 \\
\dot{\rho} \\
\dot{m}\end{array}$ & 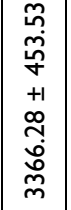 & 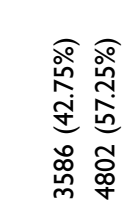 & 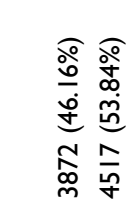 & 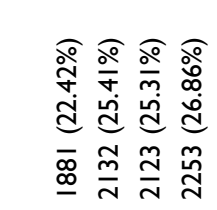 \\
\hline & $a$ & $\begin{array}{l}\overline{8} \\
\text { ì } \\
\text { v }\end{array}$ & o̊̀ & 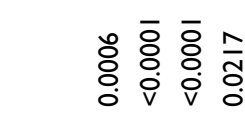 & $\begin{array}{l}\overline{8} \\
\text { v } \\
\text { v }\end{array}$ & $\begin{array}{l}\frac{\sigma}{\sigma} \\
\frac{\sigma}{0} \\
\end{array}$ & 㫣 & $\begin{array}{l}\overline{8} \\
\text { ¿े } \\
\text { v }\end{array}$ & 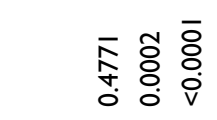 \\
\hline & 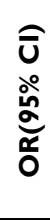 & 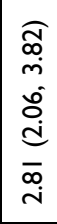 & 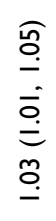 & 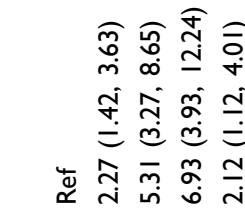 & 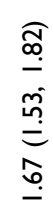 & $\infty$ & 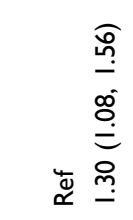 & 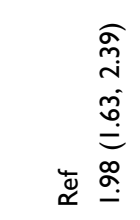 & 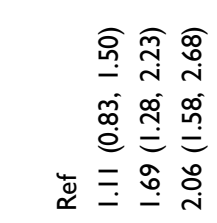 \\
\hline & $\frac{\mathscr{0}}{\stackrel{5}{\rho}}$ & 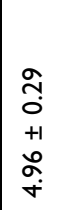 & $\begin{array}{l}\stackrel{\circ}{\circ} \\
\stackrel{+}{+} \\
+1 \\
\stackrel{n}{0} \\
\stackrel{\sim}{\sigma}\end{array}$ & 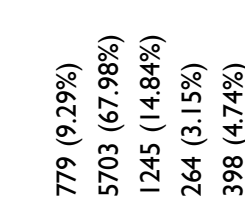 & 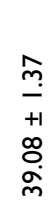 & 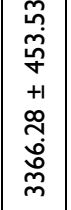 & 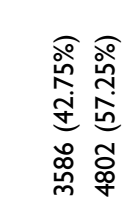 & 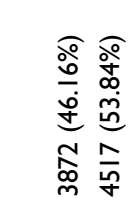 & 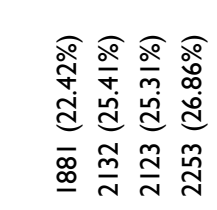 \\
\hline \multirow{3}{*}{ 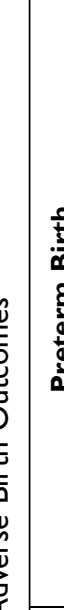 } & $a$ & চे & 芯 & 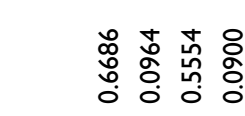 & $\begin{array}{l}\bar{o} \\
\dot{0} \\
\text { v }\end{array}$ & $\begin{array}{l}\bar{\delta} \\
\text { o } \\
\text { v }\end{array}$ & $\begin{array}{l}\overline{8} \\
\dot{0} \\
\dot{v}\end{array}$ & $\begin{array}{l}\stackrel{2}{\vdots} \\
0 \\
0\end{array}$ & 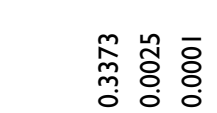 \\
\hline & $\begin{array}{l}\text { चิ } \\
\text { ڤें } \\
\text { ỡ } \\
\text { ô }\end{array}$ & 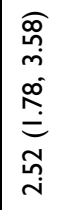 & 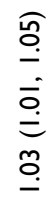 & 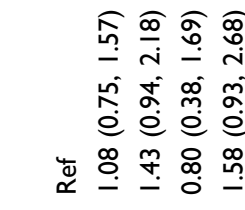 & $\begin{array}{l}\widehat{0} \\
0 \\
\text { o. } \\
0 \\
\text { ¿ } \\
0\end{array}$ & 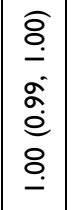 & 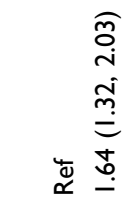 & 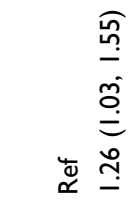 & 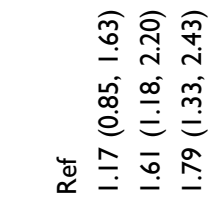 \\
\hline & 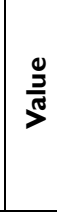 & $\begin{array}{l}\text { స్ } \\
0 \\
+1 \\
\circ \\
\circ \\
+\end{array}$ & $\begin{array}{l}\stackrel{0}{0} \\
+ \\
+1 \\
+1 \\
\stackrel{0}{0} \\
\stackrel{i}{0}\end{array}$ & 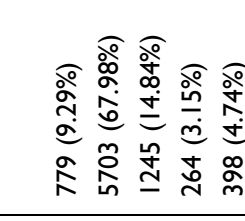 & $\begin{array}{l}\hat{m} \\
\stackrel{n}{+1} \\
+1 \\
\infty \\
\stackrel{\sigma}{\dot{m}}\end{array}$ & 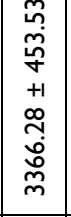 & 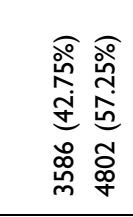 & 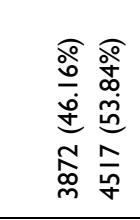 & 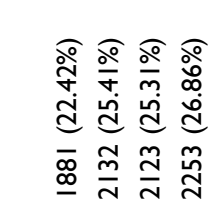 \\
\hline & & 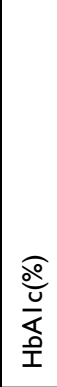 & 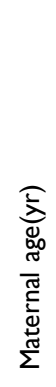 & 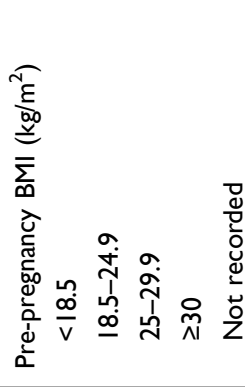 & 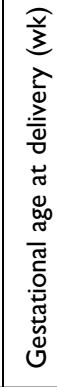 & 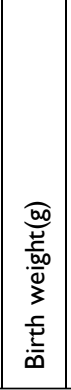 & 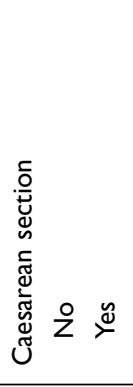 & 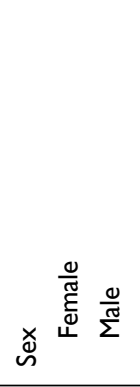 & 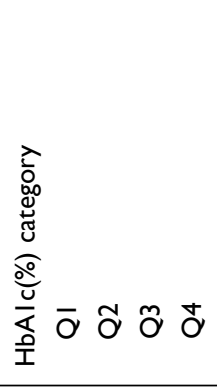 \\
\hline
\end{tabular}




\section{Results of Logistic Regression Analyses}

Table 3 shows the associations of the HbAlc value during midpregnancy with adverse birth outcomes. Two adjustment models were constructed to analyze the independent effect of HbAlc on adverse birth outcomes (multivariate binary logistic regression analysis), including effect size (adjusted OR) and 95\% CI. The results of the adjustment model I (adjusted according to maternal age and prepregnancy BMI) showed that $\mathrm{HbAlc}$ is significantlyand positively correlated with increased risk of preterm birth (adjusted OR: 2.39 and 95\% CI: 1.673.44), macrosomia (adjusted OR: 1.91 and 95\% CI: 1.39-2.63), and LGA (adjusted OR: 1.64 and 95\% CI: 1.33-2.02). The results of the adjustment model II (gestational age, cesarean section and neonatal gender were added on the basis of adjusting model I, but the preterm birth model did not include gestational age) demonstrated that $\mathrm{HbA} 1 \mathrm{c}$ remains significantly and positively correlated with the increased risk of preterm birth (OR: 2.37 and 95\% CI: 1.65-3.41), macrosomia (OR: 2.25 and 95\% CI: 1.61-3.13), and LGA (OR: 1.82 and 95\% CI: 1.47-2.25).

The relationship between HbAlc and adverse birth outcomes was similar between women with prepregnancy BMIs of $\geq 25$ and $<25 \mathrm{~kg} / \mathrm{m}^{2}$ but more significant in pregnant women with prepregnancy BMI $<25 \mathrm{~kg} / \mathrm{m}^{2}$ (Figure 2).

$\mathrm{HbA1c}$ was converted from a continuous variable to a categorical variable (quartiles of $\mathrm{HbAlc}$ ) for the sensitivity analysis. The $P$ value for the trend of $\mathrm{HbAlc}$ with categorical variables in the fully adjusted model was consistent with the result when $\mathrm{HbAlc}$ was a continuous variable. Additionally, the trend of the effect size in different $\mathrm{HbA1c}$ groups was nonequidistant. The positive correlation between $\mathrm{HbA} 1 \mathrm{c}$ during pregnancy and adverse birth outcomes after excluding prediabetic pregnant women demonstrated no significant change (HbAlc value was 5.7-6.4\%) (Schedule 1)

\section{Discussion}

This study primarily aimed to investigate the relationship between HbAlc and adverse birth outcomes during midpregnancy. We found that elevated $\mathrm{HbAlc}$ values during midpregnancy are associated with increased risk of preterm birth, macrosomia, and LGA. HbAlc and adverse birth outcomes were significant in women with a prepregnancy BMI of $<25 \mathrm{~kg} / \mathrm{m}^{2}$.
HbA1c can be used as a clinical test index, an independent GDM predictor, and in association with other standard diagnostic tests for GDM diagnosis. ${ }^{22-24}$ Many recent reports on the relationship between $\mathrm{HbAlc}$ and adverse pregnancy outcomes in women with GDM confirmed that a correlation exists between the $\mathrm{HbAlc}$ value and adverse pregnancy outcomes. ${ }^{10,25,26}$

Ho et al enrolled 1989 pregnant Taiwanese women, ${ }^{25}$ the results showed that the midpregnancy $\mathrm{HbAlc}$ value was significantly associated with increased risks of preterm delivery and macrosomia (the odds ratio [OR] ranges were $1.31-5.16$ and 2.22-27.86). In a study by Iwama and colleagues, ${ }^{27}$ the adjusted odds ratios per $1 \%(11 \mathrm{mmol} /$ mol) increase in HbAlc level were 1.30 (95\% CI: 1.12 1.50) for preterm birth, 1.95 (95\% CI: 1.42-2.70) for macrosomia, 1.15 (95\% CI: 1.04-1.28) for LGA. A longitudinal study conducted in New Zealand showed that high HbAlc level below the diagnostic criteria of GDM in pregnant women were associated with preterm birth and LGA, but not with macrosomia ${ }^{17}$ Hence, the influence of $\mathrm{HbA1c}$ values of pregnant non-GDM women on adverse birth outcomes remains unclear. Differences between the results of previous studies and our findings may be due to the following reasons. First, monitoring of $\mathrm{HbAlc}$ at different gestational periods (early and midterm) showed that significant differences exist in $\mathrm{HbAlc}$ values among the three gestational periods. Second, subjects belonged to different ethnic groups. Finally, differences in $\mathrm{HbAlc}$ estimation and standardized methods may affect their results.

The subclinical grouping showed that women with BMI $<25 \mathrm{~kg} / \mathrm{m} 2$ showed a more significant relationship with preterm birth, macrosomia, and LGA than women with BMI $\geq 25 \mathrm{~kg} / \mathrm{m} 2$. The relationship between $\mathrm{HbA} 1 \mathrm{c}$ and adverse birth outcomes was similar between women with prepregnancy BMI of $\geq 25$ and $<25 \mathrm{~kg} / \mathrm{m} 2$ but more significant in pregnant women with prepregnancy BMI $<$ $25 \mathrm{~kg} / \mathrm{m} 2$. Among them, the OR of preterm birth (2.39 and $95 \%$ CI: $1.67-3.44$ ) in BMI $\geq 25 \mathrm{~kg} / \mathrm{m} 2$, which is consistent with the results of $\mathrm{Bi}$, et al [1]. The macrosomia (OR: 2.37 and $95 \%$ CI: $1.59-3.55$ ) and LGA (OR: 2.05 and $95 \%$ CI: 1.60-2.64) results are inconsistent, which may be related to their small sample size.

Some research results show that ${ }^{28,29}$ pregnant women who are underweight before pregnancy will significantly increase the risk of preterm birth, and obesity will slightly increase the risk of preterm birth. A large cohort study of 536,098 Chinese pregnant women in rural China showed 


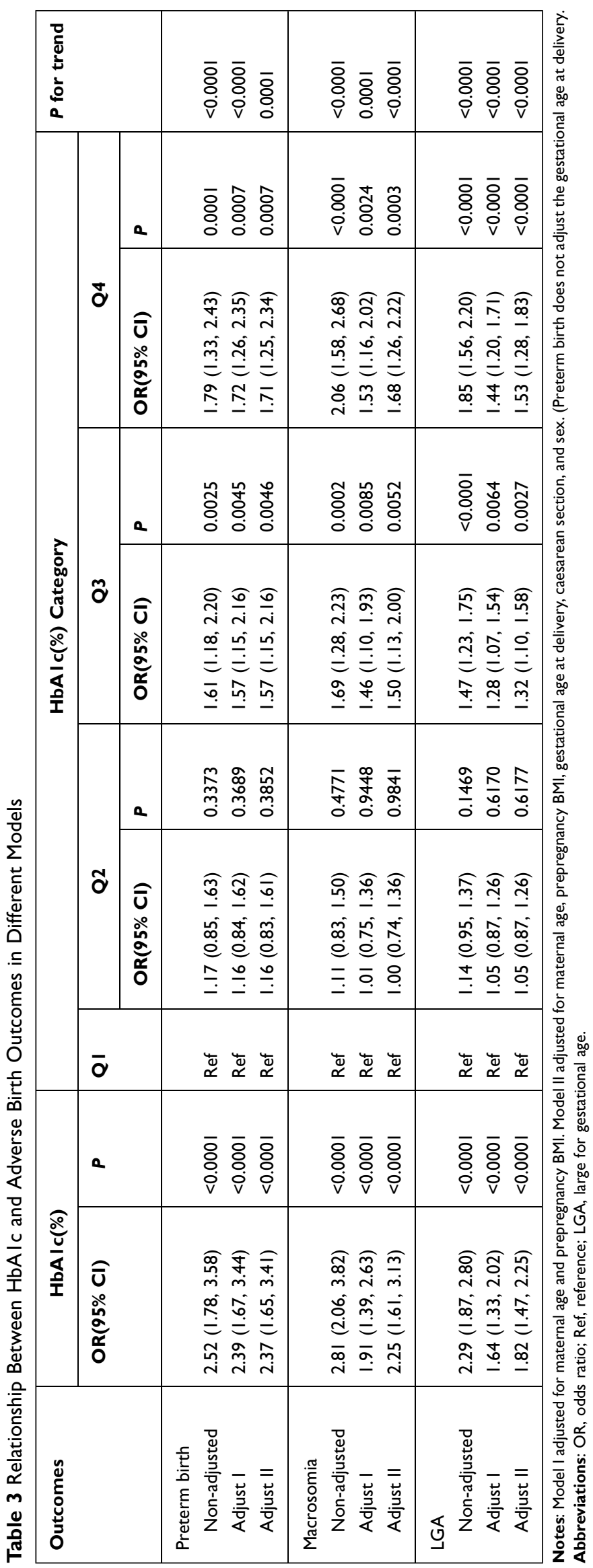


that the prevalence of underweight individuals significantly increased and both extremely high and low maternal prepregnancy BMI values have a significant association with adverse pregnancy outcomes. ${ }^{30}$ This is also consistent with the results of our study. Pre-pregnancy BMI $<25 \mathrm{~kg} /$ $\mathrm{m}^{2}$ and the higher incidence of preterm birth may be due to the poor nutritional status of pregnant and lying-in women. Women lacking certain nutrients were susceptible to chronic infection and inflammation, which led to an increased risk of PTB. The mechanism by which macrosomia and LGA were more likely to occur with BMI less than $25 \mathrm{~kg} / \mathrm{m}^{2}$ before pregnancy was still unclear, and further research was needed to clarify the mechanism in future work.

The following are the limitations of this study. First, this study is a single-center retrospective investigation because only Chinese subjects were included; therefore, universality and extrapolation of findings are impossible. Second, relative data may be inaccurate because some birth weights were only accurate for percentiles rather than individuals. Third, HbA1c values were collected at different times; hence, the comparison of the association between HbA1c and adverse birth outcomes through a control cohort is infeasible. Fourth, the populations we currently include were all tested for $\mathrm{HbAlc}$ in the second trimester, and cannot be extrapolated to those who have not tested HbA1c.

\section{Conclusion}

Elevated normal-range HbAlc values during midpregnancy are positively correlated with the risk of adverse birth outcomes even within the normal range. Elevated HbAlc values may increase the risk of adverse birth outcomes.

\section{Acknowledgments}

The authors thank all the staff members of the Affiliated Hospital of Jining Medical University in China.

\section{Funding}

This study was supported by the Research Fund for Academician Lin He New Medicine in China (Grant no. JYHL2019FMS14) and Scientific Research Foundation of Doctor in Jining Medical University.

\section{Disclosure}

The authors declare no conflicts of interest.

\section{References}

1. Tsegaye B, Kassa A. Prevalence of adverse birth outcome and associated factors among women who delivered in Hawassa town governmental health institutions, south Ethiopia, in 2017. Reprod Health. 2018;15(1):193. doi:10.1186/s12978-018-0631-3

2. Howson CP, Kinney MV, Mc Dougall L, et al.; Born Too Soon Preterm Birth Action Group. Born too soon: preterm birth matters. Reprod Health. 2013;10:S1.

3. Rubens CE, Gravett MG, Victora CG, et al. Global report on preterm birth and stillbirth (7 of 7): mobilizing resources to accelerate innovative solutions (global action agenda). BMC Pregnancy Childbirth. 2010;10(S1):S1-7. doi:10.1186/1471-2393-10-S1-S7

4. Crowther CA, Hiller JE, Moss JR, et al. Effect of treatment of gestational diabetes mellitus on pregnancy outcomes. $N$ Engl J Med. 2005;352(24):2477-2486. doi:10.1056/NEJMoa042973

5. Yu H, Wang J, Shrestha Y, et al. Importance of early elevated maternal HbA1c levels in identifying adverse fetal and neonatal events. Placenta. 2019;86:28-34. doi:10.1016/j.placenta.2019.07.008

6. Metzger BE, Lowe LP, Sacks DA, et al.; HAPO Study Cooperative Research Group. Hyperglycemia and adverse pregnancy outcomes. N Engl J Med. 2008;358:1991-2002.

7. Cho HY, Jung I, Kim SJ. The association between maternal hyperglycemia and perinatal outcomes in gestational diabetes mellitus patients: a Retrospective Cohort Study. Medicine (Baltimore). 2016;95(36):e4712. doi:10.1056/NEJMoa0707943

8. Shobha P, Mathen S, Abraham J. Glycosylated hemoglobin values in nondiabetic pregnant women in the third trimester and adverse fetal outcomes: an Observational Study. J Fam Med Prim Care. 2016;5 (3):646-651. doi:10.4103/2249-4863.197313

9. International Expert Committee. International expert committee report on the role of the A1C assay in the diagnosis of diabetes. Diabetes Care. 2009;32(7):1327-1334. doi:10.2337/dc09-9033

10. Metzger BE, Gabbe SG, Persson B, et al.; International Association of Diabetes and Pregnancy Study Groups Consensus Panel. International association of diabetes and pregnancy study groups recommendations on the diagnosis and classification of hyperglycemia in pregnancy. Diabetes Care. 2010;33(7):676-682. doi:10.2337/ dc09-1848

11. Joshu CE, Prizment AE, Dluzniewski PJ, et al. Glycated hemoglobin and cancer incidence and mortality in the Atherosclerosis in Communities (ARIC) Study, 1990-2006. Int J Cancer. 2012;131 (7):1667-1677. doi:10.1002/ijc.27394

12. Li H, Cui Y, Zhu Y, et al. Association of high normal HbAlc and TSH levels with the risk of CHD: a 10-Year Cohort Study and SVM analysis. Sci Rep. 2017;7(1):45406. doi:10.1038/srep45406

13. Ferroni P, Formica V, Della-Morte D, et al. Prognostic value of glycated hemoglobin in colorectal cancer. World $J$ Gastroenterol. 2016;22(45):9984-9993. doi:10.3748/wjg.v22.i45.9984

14. Bi J, Ji C, Wu Y, et al. Association between maternal normal range HbA1c values and adverse birth outcomes. J Clin Endocrinol Metab. 2020;105(6):105. doi:10.1210/clinem/dgaa127

15. Mañé L, Flores-le Roux JA, Benaiges D, et al. Role of first-trimester $\mathrm{HbA} 1 \mathrm{c}$ as a predictor of adverse obstetric outcomes in a multiethnic cohort. J Clin Endocrinol Metab. 2017;102(2):390-397. doi:10.1055/ s-0038-1675619

16. Chen L, Pocobelli G, Yu O, et al. Early pregnancy hemoglobin A1C and pregnancy outcomes: a Population-Based Study. Am J Perinatol. 2019;36(10):1045-1053. doi:10.1055/s-0038-1675619

17. Hughes RC, Rowan J, Florkowski CM. Is there a role for HbA1c in pregnancy? Curr Diab Rep. 2016;16(1):5. doi:10.1007/s11892-0150698-y

18. Dall'Asta A, Lees C. Early second-trimester fetal growth restriction and adverse perinatal outcomes. Obstet Gynecol. 2018;131 (4):739-740. doi:10.1097/AOG.0000000000002548 
19. Araujo Júnior E, Peixoto AB, Zamarian AC, et al. Macrosomia. Best Pract Res Clin Obstet Gynaecol. 2017;38:83-96. doi:10.1016/j. bpobgyn.2016.08.003.

20. Dai L, Deng C, Li Y, et al. Birth weight reference percentiles for Chinese. PLoS One. 2014;9(8):e104779. doi:10.1371/journal. pone.0104779

21. Gupta PC, Subramoney S. Smokeless tobacco use, birth weight, and gestational age: Population Based, Prospective Cohort Study of 1217 women in Mumbai, India. BMJ. 2004;328(7455):1538. doi:10.1136/ bmj.38113.687882.EB

22. Punnose J, Malhotra RK, Sukhija K, et al. Glycated haemoglobin in the first trimester: a predictor of gestational diabetes mellitus in pregnant Asian Indian women. Diabetes Res Clin Pract. 2020;159:107953. doi:10.1016/j.diabres.2019.107953

23. Renz PB, Chume FC, Timm JRT, et al. Diagnostic accuracy of glycated hemoglobin for gestational diabetes mellitus: a systematic review and meta-analysis. Clin Chem Lab Med. 2019;57 (10):1435-1449. doi:10.1515/cclm-2018-1191

24. Mousavi SN, Kamali K, Mirbazel M, et al. The best cut-off value for $\mathrm{HbA1c}$ as a screening tool in Iranian women with gestational diabetes mellitus. J Fam Reprod Health. 2017;11(1):37-42. PMID: 29114267; PMCID: PMC5664988.

25. Ho YR, Wang P, Lu MC, et al. Associations of mid-pregnancy $\mathrm{HbA1c}$ with gestational diabetes and risk of adverse pregnancy outcomes in high-risk Taiwanese women. PLoS One. 2017;12 (5):0177563. doi:10.1371/journal.pone.0177563
26. Ye M, Liu Y, Cao X, et al. The utility of HbAlc for screening gestational diabetes mellitus and its relationship with adverse pregnancy outcomes. Diabetes Res Clin Pract. 2016;114:43-49. doi:10.1016/j.diabres.2016.02.007

27. Iwama N, Sugiyama T, Metoki H, et al.; Japan Environment and Children's Study Group. Associations between glycosylated hemoglobin level at less than 24 weeks of gestation and adverse pregnancy outcomes in Japan: the Japan Environment and Children's Study (JECS). Diabetes Res Clin Pract. 2020;169:108377. doi:10.1016/j. diabres.2020.108377

28. Enomoto K, Aoki S, Toma R, et al. Pregnancy outcomes based on pre-pregnancy body mass index in Japanese women. PLoS One. 2016;11(6):0157081. doi:10.1371/journal.pone.0157081

29. Khatibi A, Brantsaeter AL, Sengpiel V, et al. Prepregnancy maternal body mass index and preterm delivery. Am J Obstet Gynecol. 2012;207(3):212.e1-7. doi:10.1016/j.ajog.2012.06.002.

30. Pan Y, Zhang S, Wang Q, et al. Investigating the association between prepregnancy body mass index and adverse pregnancy outcomes: a Large Cohort Study of 536098 Chinese pregnant women in rural China. BMJ Open. 2016;6(7):011227. doi:10.1136/bmjopen-2016011227
International Journal of General Medicine

\section{Publish your work in this journal}

The International Journal of General Medicine is an international, peer-reviewed open-access journal that focuses on general and internal medicine, pathogenesis, epidemiology, diagnosis, monitoring and treatment protocols. The journal is characterized by the rapid reporting of reviews, original research and clinical studies

\section{Dovepress}

across all disease areas. The manuscript management system is completely online and includes a very quick and fair peer-review system, which is all easy to use. Visit http://www.dovepress.com/ testimonials.php to read real quotes from published authors. 